Bachkirova, T. (2016) 'A new perspective on self-deception for applied purposes', New Ideas in Psychology, 43. pp. $1-9$.

DOI: https://doi.org/10.1016/i.newideapsych.2016.02.004

This document is the authors' Accepted Manuscript.

License: https://creativecommons.org/licenses/by-nc-nd/4.0

Available from RADAR: https://radar.brookes.ac.uk/radar/items/18079995-e614-48ec-a8ca-dd1c81c8ed39/1/

Copyright (C) and Moral Rights are retained by the author(s) and/ or other copyright owners unless otherwise waved in a license stated or linked to above. A copy can be downloaded for personal non-commercial research or study, without prior permission or charge. This item cannot be reproduced or quoted extensively from without first obtaining permission in writing from the copyright holder(s). The content must not be changed in any way or sold commercially in any format or medium without the formal permission of the copyright holders. 


\title{
A new perspective on self-deception for applied purposes
}

Tatiana Bachkirova, Oxford Brookes University, UK

\begin{abstract}
The concept of self-deception attracts the attention of many fields of knowledge, however very few attempts have been made to compare and contrast these positions for applied purposes. This paper provides theoretical analysis of the literature on selfdeception from a pragmatic perspective that informs personal development work on recognizing and minimizing self-deception and helping practices such as counselling and coaching. Five distinct strands of thought on self-deception are identified and discussed with their implications for personal development work revealing significant diversity in the views on self-deception. The paper suggests that what is missing in current theories of self-deception is consideration of self in self-deceivers. In conjunction with theories of adult development this paper suggests a new developmental perspective on self-deception that highlights individual differences according to developmental stages providing a unique contribution to current debates about the concept and potential approaches for influencing self-deception. From the pragmatic perspective the paper also proposes a synthesis of the discussed theoretical perspectives in the form of a conceptual model that demonstrates the complexity and multidimensionality of self-deception.
\end{abstract}

Keywords: self-deception, pragmatic perspective, self, developmental perspective, helping practices 
The concept of self-deception has a long history in psychology and philosophy and continues to inspire new perspectives and explanations of the paradox that it entails. The idea that the mind can conceal information from itself is puzzling and disturbing, producing different conceptions of self-deception and different views on the consequences of it. For Pinker (2008), for example, documenting the human propensity to self-deception and similar phenomena is one of the greatest achievements in psychology because they are "the source of much of the complexity, and tragedy, of human life" (Pinker, 2008, p. 184). Others support the studies of self-deception but argue that a degree of it is always present and may even be beneficial not only for individuals but for the survival of species (e.g. Rorty, 1994; Von Hippel and Trivers, 2011). There are also those who simply reject the idea of the existence of this phenomenon (e.g. Gergen, 1985). The implications of such positions for everyday living, wellbeing and human development may differ significantly. However, few attempts have been made to compare these positions and explore them for applied purposes (Fingarette, 2000).

It is interesting that in the history of human thought self-deception was initially explored with a view to finding a way to overcome it. In the existential philosophy of Sartre (1956) self-deception was discussed as 'bad faith'. It was seen as a refusal to reflect and to take responsibility for the engagements with the world which were apparent, but the person would not recognize them as his/her own. The intention to live authentically, Sartre argued, could help to defeat 'bad faith' through disciplined self-analysis. In the legacy of Freud (1923/1962), the concepts of unconscious defense mechanisms, although associated mainly with pathology, also had to be uncovered in psychoanalysis for the benefit of the client who was engaged in self-deception as a strategy of dealing with anxiety. However, more recent literature, although expanding the array of explanations of self-deception, has 
seemingly lost interest in this pragmatic aim: to understand this phenomenon in order to minimize it or live with it.

What becomes fairly transparent in comparing significantly different current conceptualizations of self-deception is that the differences and similarities between them are associated with different positions on the self, which in some cases are clearly stated and in others are implicit. Although the variety of these positions is not surprising given the spectrum of perspectives on the self, each of their proponents are able to provide supporting evidence from various research studies, however limited. This might mean that much of the empirical data may be interpreted according to the position taken, or that many perspectives on self-deception can have valid points. In this case, the value of such diversity could be utilized from a pragmatic perspective.

The paper will begin with an examination of the concept of self-deception and the paradoxes it entails in order to establish the nature of the problem that it aims to address. The second part of the paper will discuss a range of distinct perspectives on self-deception in terms of their explicit or potential implications for individuals who do not wish to deceive themselves and for professionals who assist individuals in their quest for development and/or wellbeing. Although a significant diversity in viewing self-deception will be highlighted the aim will not be to solve the conundrum that self-deception presents but to point out how it has arisen in broad terms.

In the third part of the paper it will be argued that all of the presented traditions are missing an important perspective - the self of the self-deceiver. With the focus on the self an additional theoretical position on self-deception is proposed. I will argue that this developmental perspective on self-deception provides a unique approach to unresolved conceptual issues and leads to important implications for practice. The pragmatic stance of the paper allows for integration of the discussed positions of self-deception into a meta- 
model that reflects the complexity of this phenomenon and the value inherent in the rich diversity of the existing perspectives.

\section{Understanding self-deception}

Much of the debate in the literature is about defining the necessary and sufficient conditions for self-deception and differentiating self-deception from other concepts, such as wishful thinking, self-serving bias, cognitive dissonance or defense mechanisms of the ego (e.g. Fingarette, 2000; Rorty, 1994; Mele, 2001). It is recognized, for example, that selfdeception is not the same as biased information processing or errors in logic, which are sometimes presented as self-deception.

1) The first condition that suggests self-deception is present is holding a belief that contradicts the information/knowledge that the individual possesses at the same time (Demos, 1960). However, this is not a sufficient condition: we filter information for many different reasons and can hold inconsistent beliefs without noticing this. This could be simply ignorance rather than self-deception. 2) To be considered as self-deception many authors claim that this belief should be persistent and 3) that the person should be motivated to keep it (Gur \& Sackeim, 1979; Fingarette, 2000). 4) In addition the individual should be active: "acting in ways that keep one uninformed about unwanted information" (Bandura, 2011, p.16). Moreover, Lewis (1996) observes that in the literature "the deception is always manifest in what is articulated, while unacknowledged (not-p) is that which is veritable and pure" (pp. 51-52) - the view that led him to defend a different explanation of self-deception.

It is important to notice that traditional explanations of self-deception are modeled on intentional other-deception (e.g. Davidson, 1985) - a premise that led to useful questions, but also to paradoxes that had to be addressed. Mele (2001) described these paradoxes as static and dynamic puzzles. The static puzzle is about how the self can be 
both aware and not aware of $p$ at the same time. The dynamic puzzle is about intentionality: if self-deception is intentional and strategic how can it fail in undermining itself? The agent's knowledge of what they are up to should get in the way. But if it is not intentional how do they succeed? One of the typical approaches in the literature to address these paradoxes is temporal or psychological partitioning that separates two opposing beliefs in terms of the time of experiencing or via a divided model of self/consciousness (Clegg \& Moissinac, 2005)

The partitioning approach to self-deception addresses the static paradox by dividing the agent into two or more sub-agents. Each of them can hold incompatible beliefs. The dynamic paradox is resolved by postulating that the deceived sub-agent cannot access the deceiving sub-agent's activities (Marraffa, 2012). Freud (1930/2002), for example, was not only the first partitionist, but someone who significantly influenced the persistent view on self-deception and self, which is based on the dominant role of consciousness in human engagement with the world. However, it is only now in the philosophical literature that a shift can be noticed from seeing self-deception as a temporary impairment of normal beliefforming processes (a position associated with more prominent role of introspective consciousness) to the more naturalistic and accepting view of self-deception as a natural inclination of the human mind, a property inherent to belief-formation mechanisms (Rorty, 1994; Bayne and Fernández, 2009; Marraffa, 2012). This shift was clearly fueled by findings in neuroscience that advocate that the working of the brain and mind are more modular and unconscious (e.g. Gazzaniga, 1992; Martindale, 1980).

Modularity suggests that the mind consists of a large number of functionally specialized goal-oriented programs that can be isolated from one another. It provides an explanation of cases in which two mutually inconsistent representations coexist within the same mind. With this modular view, the co-existence of mutually inconsistent 
representations presents no difficulties as a result of informational encapsulation (Fodor, 1983; Barrett, 2005; Tooby \& Cosmides, 1992; Kurzban, 2011). As Pinker (1997) said, "the truth is useful, so it should be registered somewhere in the mind, walled off from the parts that interact with other people" (p. 421). This means that in a modular self, selfdeception is strategic. Both conscious and non-conscious goals, once taking a center stage, “exert temporary downstream effects upon the individual's information processing and behaviors in ways that facilitate successful pursuit of that goal" (Huang \& Bargh, 2011, p. 27; Kenrick \& White, 2011; Martindale, 1980). These modular systems are not deceiving each other - they are simply operating with a certain degree of autonomy. Some authors speculate that self-deception may be a natural consequence of the autonomous goal operation that characterized our pre-conscious past (Kurzban, 2011; Huang \& Bargh, 2011).

The idea of partitioning is arguably supported by empirical studies that suggest that by acting independently subsystems can produce outcomes that may be considered deceptive. For example, it was shown that when the goal (need) is active, people perceive goal-factual stimuli as bigger, closer and more likable (Veltkamp et al, 2008; Balcetis \& Dunning, 2010; Ferguson, 2008; Bruner \& Goodman 1947). It could be postulated then that when the need is satisfied activation stops inhibiting mental representations involved in pursuit of the goal and memory brings back the images that support other goals. The person experiences this as the realization of what was known' long before but for a while was 'covered' by self-deception.

When self-deception is associated with nuances of information processing, various attempts are made to describe mechanisms of its occurrence. Von Hippel and Trivers (2011) make a case for classification of mechanisms of self-deception as employed at different stages of information processing. For example, at the stage of information 
gathering self-deception is manifested in selected attention, e.g. biased information search (amount of search, selective searching and selective attention) and typical biased interpretation. For example, we take credit for successes but deny blame for failures (Zuckerman, 1984), accept praise uncritically but receive criticism skeptically, looking for a reason to dismiss it (Kunda, 1990). At the middle stage of information processing selfdeception is sustained by obfuscating the truth and misremembering. For example, Conway and Ross (1984) demonstrated that after taking a study skills class, people misremembered their prior study skills as lower than they had rated them originally, thereby supporting their belief that their skills have improved (Von Hippel \& Trivers, 2011). Other studies show that we can persuade ourselves that our good traits are exceptional while our flaws are common and shared by many other people (Campbell, 1986; Suls \& Wan, 1987). There are also many ways of convincing the self in a particular narrative amongst possible others (Lewis, 1996; Tenbrunsell \& Messick, 2004) which in other traditions is called rationalization.

There is broad agreement in the literature that for self-deception to be a consistent strategy and an enduring capacity of individuals, there should be a gain in deceiving oneself. On a personal scale the gain is usually about avoiding distress and/or acquiring benefits such as enhanced self-image. Some authors make more emphasis on the avoidance strategy (Freud, 1938/1950; Fingarette, 2000; Sackeim, 1983), other focus on the role of gained benefits with more variations as to what the nature of these benefits is (Starek \& Keating, 1991; Campbell, 1986; Suls \& Wan, 1987). On the other hand, other authors, e.g. Von Hippel and Trivers (2011) argue against the traditional view on self-deception as a defensive strategy with hedonic consequences. They suggest that the strategy of selfdeception is offensive rather than defensive. Hedonic interests are only a means to an end. According to these authors, self-deception has developed to better conceal deception and so 
the main benefit of self-deception is performance enhancement. When someone experiences a doubt or lack of self-belief, deception of others in one's abilities is more convincing if accompanied by self-deception. In this case it is less likely that deception will be uncovered. Von Hippel and Trivers (2011) provide many examples of such benefits claiming that this strategy provides individuals with personal and evolutionary advantages, also claiming that self-deception enhances immune function and leads to greater interpersonal success. In support of this view Kenrick and White (2011, p. 29) argue that any "functional explanation cannot begin and end inside a person's head - people do not strive to "feel good" for its own sake, they feel good when they act in ways that, on average, increased their ancestors' chances of survival and reproduction".

Alongside the potential benefits of self-deception there are discussions about the various costs of self-deception, not only for a self-deceiving individual but also for others involved. The first warning about the cost of self-deception could be traced back to Freud (1938/1950) who said that the penalty for repression is repetition. For many other authors (e.g. Funder, 2011; Preti \& Miotto, 2006), including Von Hippel and Trivers (2011), the loss of information integrity seems to be the main cost of self-deception. Considering that commitment to reality and honesty is important in perception and in communication, selfdeception can be effective when it represents small and believable deviations from reality. In this regard Von Hippel and Trivers (2011, p. 43) go as far as even suggesting that a welltuned self-deceptive organism would likely be one that biases reality by $20 \%$ in the favored direction proportionally to $80 \%$ of self-verification strivings.

1.1. Themes from the applied research

In comparison to the above themes in the literature that are widely discussed, what attracts much less attention but is of interest for a pragmatist are individual differences in terms of the tendency for self-deception and the ways of influencing it. There are studies in 
psychology that define self-deception as a dispositional tendency to have an unrealistically positive self-image (Sackheim, 1983) claiming that it is a global stable trait (Lee \& Klein, 2002). They measure self-deception on, for example, a 20-items Self-Deception scale of Paulhus' Balanced Inventory of Desirable Responding (BIDR, Version 6, Paulhus, 1991). Although such measures might be valuable in assessing the degree of individual tendencies, the claim of stability of these tendencies in all circumstances is questionable and makes little contribution to the interests of those who wish to change or influence these tendencies.

In the psychoanalytical literature (Vaillant, 1992) a range of empirical studies, including longitudinal, show that the nature of defense mechanisms changes throughout the life time of an individual. The spectrum of change begins from pathology and immature defenses (e.g. denial, projection and acting out) moving gradually to more mature defenses such as suppression, sublimation and humor (Vaillant, 1992, pp. 96-97). Similar findings are documented in the field of adult development (Loevinger, 1976; Kegan, 1982, 1994; Cook-Greuter, 1999). Although these findings are significant in illustrating the opportunity for self-deception to change they indicate only initial steps towards understanding how self-deception can be minimized or whether influencing self-deception is possible at all.

There is at the same time an area of applied philosophy in the educational literature that is concerned with self-deception: teaching critical thinking. Whisner (1993) for example, suggests several educational strategies to overcome the tendency of students to engage in rationalization and self-deception. However, it appears that Whisner equates selfdeception with persistent beliefs and aims to improve appraisal skills and to address socalled motivational deficiencies mainly by engaging students in 'correct reasoning' (1993, p. 310). Apart from overestimating the power of reasoning in self-deception, his strategy of appealing to students' moral convictions seems highly questionable. 
In the psychotherapeutic literature, other than already mentioned studies of defense mechanisms, self-deception in clients is also addressed under the umbrella of irrational beliefs in REBT (rational emotive behavior therapy) (Ellis, 1994). Irrational beliefs are identified and challenged in a similar way to critical thinking approaches by the use of reasoning. In other traditions defensiveness is considered as a sign of underlying anxiety or unacknowledged desires which may be influenced by the client-therapist's relationships or the psychotherapeutic process (Kirby, 2003; Cooper, 2005; Westland and Shinebourne, 2009). In most cases self-deception is used to describe maladaptive attitudes and behaviors that are identified by the therapist as an expert. However, Spinelli (2007) argues that not all branches of psychotherapy are the same in this respect. Narrative, social constructionists and existential psychotherapists avoid assuming an expert role and judging clients' stories as unreal, irrational or false.

Some emerging interests in self-deception can also be noticed in coaching literature (Berglas, 2002; Williams et all, 2010) with a focus on 'faulty thinking' and 'self-limiting beliefs'. The authors tend to apply strategies similar to critical thinking methods or some ideas from cognitive-behavioral therapy, treading carefully not to overstep the boundaries with counselling or psychotherapy. At the same time as coaching practitioners tend to position themselves closer to applied positive psychology rather than the psychotherapeutic field, it would seem unusual for coaches to work explicitly with self-deception when the expectation is to focus on strengths (Kauffman et al, 2010; Freire, 2013). Only developmental coaching offers some inclination to address self-deception explicitly (Bachkirova, 2011, 2013), but such approaches are in the early stages of development.

It seems therefore that literature on self-deception is mainly concerned with the understanding of the phenomenon of self-deception but much less with the implications of the new theories proposed and conceptual advances made. In the fields of applied 
knowledge, on the other hand, there are some attempts in addressing the topic of selfdeception but without consideration of the recent theories and debates. Consequently, little current theoretical influence can be noticed on applied approaches of working with individuals who want to minimize self-deception. In the following section potential implications of some distinct theoretical positions on self-deception are speculatively considered.

\section{Perspectives on self-deception and their implications for practice}

Five distinct perspectives on self-deception are described: 1) Existential philosophy; 2) the psychoanalytic approach; 3) postmodernism; 4) the evolutionary approach and 5) the neuroscience position. For consistency, presentation of each perspective will include: a) a concept of self-deception as conceived within this perspective; b) an actual or deduced view on minimizing self-deception with the opportunity of influencing it and c) potential problems with this approach.

2.1. In Existential philosophy self-deception is seen as putting oneself to sleep in one particular respect (Sartre, 1956). It is a disavowal of responsibility for some project of consciousness by refusal to reflect upon it. The self-deceiver seems to be at war with his/her self.

"It is from this perspective, so insistently favored by Sartre and other Existentialists that we see how someone, by reason of lack of spiritual courage, attempts to save his integrity at a price which amounts to surrendering, however indirectly, the very integrity that he cherishes" (Fingarette, 2000, p. 138).

Although, according to Sartre, accepting the anguish offers a possibility of acting in good faith, the expectation of change for the self-deceiver is often excessively strong and demanding in moral terms. The self-deceiver must accept his lack of moral courage and take responsibility for his engagement with the world that he does not dare to accept as his. 
Although Whisner (1993) does not present himself as an existentialist, the demand for honesty and appeal to moral values in his practical approach to eliminating self-deception seems to be similar to the message of existentialists. Apart from the development of thinking skills the self-deceiver has to be conveyed the message that "...rationalization and self-deception are incompatible with the belief that he or she is a morally good person" (1993, p. 320).

However, the role of consciousness and intellect seems overstated in the influencing of self-deception, in exactly the same way as the role of the intellectual understanding of psychological problems is overstated as a means of overcoming them (Claxton, 1997). Many therapeutic approaches, such as Gestalt (Perls, et al, 1951) show that understanding the problem by sufferers does not guarantee the ability to change. Fingarette (2000) adds to this critique another plausible argument: as it is only a person who has integrity that cares to self-deceive, then the appeals to integrity and moral concerns can only strengthen selfdeception.

\subsection{In the psychoanalytic approach defense mechanisms are defined as mental} processes that operate unconsciously to reduce painful emotions. Self-deception is seen as a defense against anxiety - actively resisting becoming conscious of a threat, tampering with reality to avoid pain (Freud, 1938/1950; Maze \& Henry, 1996). This tradition suggests the significant if not prevalent role of unconscious in the explanation of self-deception. This tradition is also of high interest to the pragmatist because it has a developed practice of working with individuals. It implies significant compassion to the self-deceiving individual, because self-deception is seen as a response to anxiety originating in early psychological trauma. The process of therapy requires re-learning through which the client re-evaluates the threatening situation within the context of significant transference relationship. 
There is obviously something to learn about influencing self-deception from the psychoanalytic tradition if the roots of self-deception are in the unconscious and the deep painful areas of the suppressed past. It is certainly important to remember a general rule of this type of work to go to the limit of one's courage, but not beyond the breaking point. However, defense mechanisms as studied in psychoanalysis represent only some types of self-deception whereas other types, as the literature shows, are about a gain rather than protection from anxiety. Similarly, the notion of the unconscious as dark and dangerous is convincingly challenged by more current explanations of human nature (e.g. Claxton, 2005, 2006). It is possible that a lighter and even more appreciative attitude to the unconscious is more beneficial for influencing self-deception.

\subsection{In Postmodernism the idea of self-deception is questioned in principle in the} process of deconstructing what is meant by the self. As for self-deception, narrative is a fundamental organizing principle for all human thought and self-deception is simply a special case of storytelling. As the mind can only entertain one story at a time "...all that is required not be aware of something is immersion in a story where that something does not exist" (Lewis, 1996, p. 60).

What can be inferred from this position that it is impossible to distinguish selfdeceiver from self-non-deceiver in objective terms. Self-deception is intriguing not because of mysterious workings of the mind, but rather because of what it says about the culture in which we live. The discrepancies between different stories presented by the individual may indicate what in other traditions is called self-deception. However, the way it can be understood and addressed during for example narrative therapy or coaching, is by exploring social context of these stories, such as a history of social interaction, social roles of individuals and discourses that influence them. 
Although this position justifiably questions the role of an independent observer in defining self-deception and highlights underestimation of the role of context in these debates, it seems to be diminishing the role of individuals themselves in the process of shifting emphasis to the role of context. For example, it does not explain why individuals themselves can recognize their self-deceptions and why they have preferences for seeing things more clearly if they can help it. There is also evidence to suggest that not only the nature of stories changes as individuals develop, but individuals at the later stages of development pay more attention to self-deception and recognize it faster (Cook-Greuter, 1999; Loevinger, 1976). However, the main problem for a pragmatist who wishes to influence self-deception is that the postmodernist position does not offer much in terms of ways to learn and change.

2.4. The evolutionary approach is another distinct position to explaining selfdeception from a wider social angle (Von Hippel \& Trivers, 2011). This explanation is radically different from others as it focuses on the benefits and adaptive value of selfdeception, suggesting that the strategy of self-deception is offensive rather than defensive. Self-deception is used to better conceal deception about one's qualities. According to Von Hippel and Trivers (2011) self-enhancement is not just feeling better about oneself, but for convincing others that the self is better than it really is, because better selves reach leadership positions, have mates, etc. There is research supporting the claim that selfdeception can contribute to the long-term wellbeing of individuals. In their work with adult bereavement Bonanno and Siddique (1999, p. 260) found that 'self-deception and emotional avoidance were consistently and robustly linked to a better outcome' in terms of wellbeing over time.

An obvious implication of this position seems to be the opposite to the original intention of this paper. If self-deception is useful there is no need to be concerned with 
minimizing it in principle. Only the balance matters and the logic of this balance is to become a "well-tuned self-deceptive organism", because "self-deception will be most effective when it represents small and believable deviations from reality (Von Hippel and Trivers, 2011, p. 43). This is strikingly different to other views on self-deception and may not fit with the way many people would wish to see themselves. Although it is difficult to argue with a position that "natural selection does not care about truth; it cares only about reproductive success" (Stich, 1990, p. 62), the strength of this position might only be applicable to the reproductive period of an individual's life. Given that we now live far beyond the stage where reproductive needs dominate how we wish to present our selves, it is a moot point as to how far such adaptive functions remain influential. In fact, some studies show that with more awareness and self-insight people wish to deceive themselves less (Cook-Greuter, 1999).

2.5. Finally, it is possible to discern another position on self-deception suggested by some neuroscientists (Kenrick \& White, 2011; Kurzban, 2011). For example, Kenrick and White (2011) argue that there is no self to be deceived and no deception or self-deception it is simply a division of labor between different information-processing and motivational modules that are specialized to perform certain functions - 'subselves', according to Martindale (1980). One part of the mind is not "deceiving" another part; these modular systems are simply operating with a certain degree of autonomy.

Although this position is well supported and makes sense, the implications for working with self-deception are unknown: how can one influence what does not seem to exist? It might not be the task of neuroscientists to respond to the needs of those who wish to minimize self-deception; however, there are many questions for this position that can be posed by the pragmatists. For example, which subself has an awareness of another subself when self-deception is identified by the person? Why does the nature of defense 
mechanisms change (Vaillant, 1992, pp. 96-97)? How is change possible at all? What changes in the subself with increased awareness of the individual? Which subself benefits from increased awareness and development?

\subsection{An overview of the problem:}

The comparative overview that is provided by this particular selection of differing approaches to understanding self-deception show that, whilst there are some similarities, the differences are highly significant. This confirms the complex nature of dealing with the phenomenon for those who experience it as a problem and wish to learn about it in order to change their tendency towards self-deception. Some of the differences in the conceptualization of self-deception are the consequence of the implicit ontological and epistemological assumptions that the authors make in their discussions of self-deception which can leave the definitions and explanations that they provide open to considerable misunderstanding. For example, Lewis (1996, p. 52) asks: if only one of the contradictory beliefs in self-deception is articulated, how do we know that the other exists? Naming the phenomenon a self-deception seems to imply the existence of an impartial observer, who knows the actual reality. This strongly suggests an objectivist perspective on self-deception which assumes an opportunity for independent knowledge of things and events. This view is incompatible with the position of social constructivists who argue for a phenomenologically faithful approach to conceptualizing self-deception that privileges the perspective of the person experiencing the phenomenon. From this perspective they even question the existence of self-deception in principle.

Notwithstanding these differences, each approach seems to provide an interesting and plausible explanation of self-deception. However, considering that this phenomenon is called self-deception it is surprising to see how little attention is paid to the self of the selfdeceiver. The examples of self-deception that are usually discussed give very little 
information about the person who is involved in self-deception. The self is somehow anonymous and only manifestations of the actual state of self-deception are described. This is the gap that needs to be addressed if we wish to help individuals to understand and minimize self-deception and help practitioners to influence this intended change.

\section{Towards a new perspective on self-deception}

\subsection{Developmental perspective}

The proposed perspective on self-deception recognizes all conditions for identifying this phenomenon, however it suggests an additional one: a consideration of the self of selfdeceivers, or more precisely - the capacities available to this person. Let us consider a classical example of people who are 'ruined' because of neglecting to look into their states of affairs, believing in no problem at all in spite of all signs to the contrary. As usual in the description of such cases no information is offered as to what kind of person is involved in this apparent self-deception. Although it is possible to envisage many, let us consider at least two. Bob always relied on others to help him out of trouble. He never held his own view on issues of importance and avoided making decisions. Neglecting his own affairs would only be a slightly amplified state of his 'normal self'. Peter is fairly independent and is usually responsible for his actions. He is a person for whom neglecting his own affairs would be out of character. In this case avoidance of looking into his affairs and imagining that everything is in order when it is not, would be a case of self-deception. We could easily imagine that one day Peter will 'wake up' and recognize this state as self-deception. However, in the case of Bob it is only a hypothetical 'responsible self' who is deceived rather than the actual 'self' and this case strictly speaking is not a case of self-deception. It is unlikely that Bob would be able to recognize actions as self-deceptive unless he undergoes a significant transformation. 
However, most of the literature on self-deception tends to consider this phenomenon in isolation, as if it can be studied independently of the individual involved. There are only fleeting remarks in the accounts of some authors that indicate this problem. For example, Darwall (1988, p. 419) invites a different interpretation of self-deception depending on individual differences and certain capabilities:

To the extent that someone lacks any independent perspective from which critically to appropriate moral standards and simply identifies them with external demands, we are, I think, less likely to think of him as self-deceiving. There will be the same sort of repression and evasive action as the self-deceiver takes, but the person will seem less responsible if he lacks some independent critical perspective. Serious selfdeception ... requires a capacity of independent critical thought (p. 419).

As in the previous example, Bob, according to his stage of development, lacks such an independent critical perspective. His evasive actions may look like self-deceptive, but it is clear that his developmental level is a more plausible explanation of his behavior than selfdeception. The latter implies that the person holds two incompatible beliefs. In this case, Bob's lack of action simply indicates his ignorance or naïve belief that the help will come as it used to.

The first proposition of the developmental perspective is that individual differences in relation to self-deception do not only indicate the degree to which individuals are prone to it, but also play an important role in identifying whether each particular case is a case of self-deception. Self-deception can be identified if the individual possesses the capacity not to be involved in these particular self-deceptive behaviors but does so nevertheless for a particular gain. It is not self-deception if a person does not have such a capacity. A second and stronger proposition suggests that for self-deception to be recognized as such the person has to have a potential to identify his/her recent 
perceptions or actions as self-deceptive 'here and now' rather than as the result of hypothetical transformation. I believe that the above condition for recognizing selfdeception (at least in its first formulation) should be added to the four identified so far in the literature.

Self-deception could be seen as a sign of temporary stepping back from the level of achieved development. A range of authors on adult development (e.g. Kegan, 1982, 1994; Torbert, 2004; Cook-Greuter, 1999) who followed in the footsteps of Freud (1938/1957), Piaget (1976), Kohlberg (1969), Perry (1970), Graves (1970), Loevinger (1976) and many others, developed theories identifying patterns in the development of individuals in relation to the cognitive ability, moral reasoning, emotional maturity, ego strength and other aspects. According to these theories development of the above capacities is incremental. However, temporary signs of regress are not unusual (Adam \& Fitch, 1982; Redmore, 1983; Westenberg \& Gjerde, 1999; Manners \& Durkin) and in some developmental theories potential for this regress is acknowledged suggesting that development is not necessarily a steady and linear progress (Cook-Greuter, 1999). It might be possible to speculate from what is known so far about self-deception that such instances of 'stepping back' happen when the need of a previous stage becomes powerfully activated. That is why self-deception is perceived as unusual and something of a 'betrayal' of the self. To summarize: self-deception consists in perceptual flaws and the behavior that perpetuates them, uncharacteristic for the achieved level of the individual's development.

A developmental perspective can provide a unique explanation about the kind of capacity that would allow or prevent an individual from noticing her own self-deception. In relation to cognitive capacity, for example, we would not call a child self-deceiver if she covers her head with a blanket and believes that nobody can see her. However, if this 'trick' is performed by a teenager it would probably qualify as such. According to various 
developmental theories which extend Piaget's (1976) model of cognitive development to adults (e.g. Perry, 1970; Kohlberg, 1969; King and Kitchener, 1994), the cognitive capacities of adults are also in the process of development from features such as basic duality in thinking to contextual relativism. Therefore, self-deception manifested for example in 'black and white' thinking would be suspected if the person demonstrating it is normally capable of thinking in a more nuanced and abstract way with an appreciation of the ambiguity of concepts and the role of context. What would confirm this case as selfdeception is a clear motive implicating that the person might benefit from seeing things in a 'black and white' way. At the same time this type of seeing things would be a normal way of thinking for another person with or without particular 'benefits'. This second person does not deceive herself when her self does not yet include these higher capacities (Bachkirova, 2013).

A more useful concept for explaining self-deception from the developmental perspective is the development of the self or ego-development which postulates the stages in the development of the self or self-identity (Loevinger, 1976; Kegan, 1982; CookGreuter, 1999). One such mechanism described by Kegan (1982) as 'Subject-Object' relation is particularly useful. Things that are Subjects are in this theory experienced by the individual as unquestioned. He or she cannot stand back and reflect on them, as they are simply part of the self. For example, some cultural norms and expectations are often Subject to people; they constitute the framework through which individuals comprehend the situation until they are able to make them an Object and explore and reflect on them. The more individuals can take as Object the more complex their worldview becomes. Kegan (1982) suggests that the shift from Subject to Object happens in relation to some important elements of the self, thus indicating a stage in their development. For example, at one of the developmental stages, relationships with others is Subject to them; they cannot 
differentiate themselves from important relationships and do not know who they are outside of the expectations of others. At a following stage their relationship becomes Object and they become capable of being a self with a sense of autonomy.

The distinction between the above stages of development is useful in identifying self-deception. Let us consider an example of a woman in a controlling and abusive relationship believing her partner that the abuse is her own fault. She hopes for a positive change with the only evidence being to the contrary. In the case of Emma this should not be considered as self-deception. She simply did not develop a sense of self separate from her important relationship. Her view of herself depends on the expectation of the important other and she sees this situation through her need to belong. She would be prone to similar beliefs and would act accordingly in other important relationships. Karina, on the other hand, is her own person and has the ability to see herself outside the relationship. Her explanation for believing her partner is rationalized as her responsibility for the situation and her belief that she can make it work. She lies to herself that it is getting better. Deeper still, may be her fear of conflict or of the prospect of being alone which is associated with a need that is more characteristic of the previous stage of development. Karina's 'not noticing' of the worsening of the situation is self-deception as 'she could see it if only she would' (Fingarette, 2000).

The above differentiation matters for practical reasons. An experienced therapist or coach would work differently with Emma and Karina. They would try to help Emma to develop her own view on the situation. It would most likely be a long-term process, which would include providing for Emma a warm and supportive relationship and helping her to develop her sense of self that is independent of others. This would hopefully lead to the development of her stronger self, the self that can see her relationship as Object and examine it. With Karina it would be possible to challenge her exaggerated sense of 
responsibility for something that is beyond her control. With her ego strength the practitioners may decide to initiate a deeper inquiry sooner than later. She could recognize her fears as a source of self-deception and identify other strengths that could help her in this situation.

\subsection{Implications of the developmental perspective}

In terms of the implications of the developmental perspective for those who wish to minimize self-deception, the above examples show the need for the individual approach in identifying and addressing self-deception. Some individual differences may be trait-like self-deceptive tendencies indicating a personality type as in cases such as narcissism. This could be seen as a horizontal dimension of individual difference in self-deception and, as personality theories suggest, these tendencies are persistent and very difficult to influence. A vertical dimension of individual differences on the other hand indicates that the developmental stage of all individuals could give a different type of insight into their selfdeception and indicate an individual approach to addressing it.

Another way to minimize self-deception would be to invest psychologically in further development of the organism as a whole in terms of all its engagements with the world. Research shows that with each level of development self-deception becomes less dramatic, more noticeable and has lighter consequences (Vaillant, 1992; Cook-Greuter, 1999). In a similar way there are specific potential strategies that may be useful for improving quality of perception in principle which Claxton calls 'perceptual re-education' (1994, p. 11). As a different strategy for personal development, simply understanding the nature of the organism and self-deception and developing better self-observation skills may increase awareness and contribute to a more appropriate attitude to oneself with lesser need for self-deception. 
The pragmatic and developmental focus of this inquiry provides an opportunity for a theoretical contribution to understanding the phenomenon of self-deception. If the presented approaches to self-deception are seen as perspectives or different lenses on this phenomenon it is possible to utilize the insight they provide and to arrive at their synthesis: a conceptual model that allows a multidimensional view on self-deception (Fig 1).

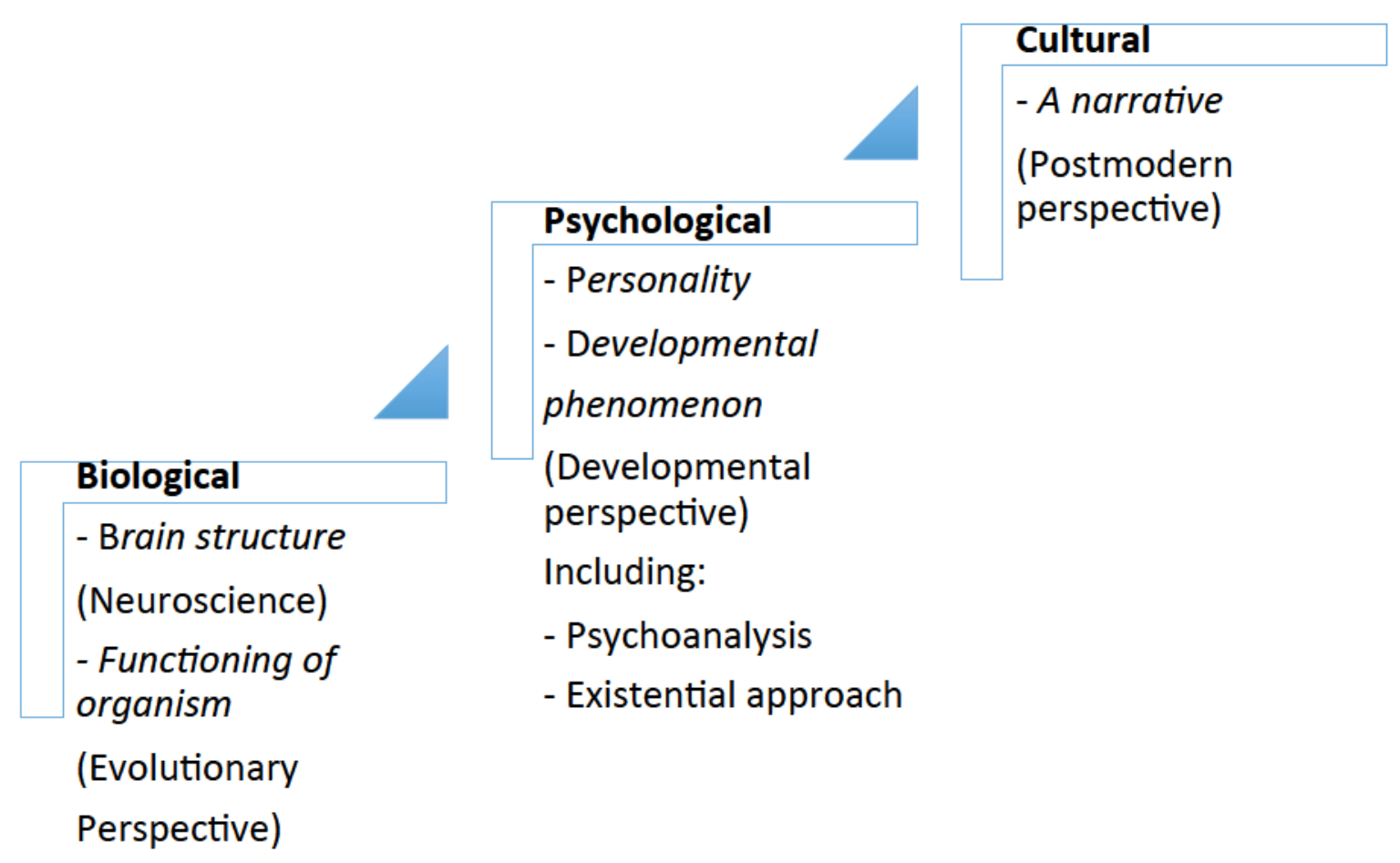

Figure 1 Levels of explanation of self-deception according to diverse perspectives

This model suggests that the discussed approaches to self-deception address it at different levels: the biological level of the individual brain structure and functioning of the organism in the evolutionary terms; the psychological level of individual differences and the cultural level that implies different conceptions of truth, self and self-knowledge. Such an approach assumes the complexity of this phenomenon without an attempt to 
reduce it to a one-dimensional explanation. The theories of self-deception on each of these levels add a particular facet to understanding self-deception without necessarily undermining another.

For example, on the biological level of the individual brain structure a developmental perspective on self-deception does not preclude us from conceptualizing the self as modular, which makes a convincing explanation of self-deception in terms of the mechanisms for coexisting contradictory beliefs. In the working of a 'modular self' as many modules perform many functions in the process of engagement with the environment some of them may strategically prevent other modules' access to particular information in order to sustain advantage in some situations. The overall capacity of this modular system is determined by the quality of each module performance. Self-deception could be seen as blind spots in perception and consequent behavior caused by a temporary dominance of some modules over others. At the same time, it is possible to speculate that there are modules responsible for evaluating the performance of the whole system that is gradually becoming more efficient. Through effective self-observation they might allow awareness of the conflict when one module occupies center stage and takes over other modules. It is these modules that may be able to recognize the filters of self-deception. These modules may also be responsible when individuals experience a sense of disappointment and concern identifying their self-deceptive tendencies and want to minimize them.

On the biological level the evolutionary perspective provides a plausible explanation for the power of sustained reproductive mechanisms for fitness that may encourage tendencies for self-deception. Although it is reasonable to assume that competitiveness for sexual conquest and status that drives deception and self-deception might become comparatively less prominent at later stages of life, the mechanisms 
described by evolutionary approach create an important background to this phenomenon for interested practitioners.

The psychological level of this framework emphasizes manifestations of the above mechanisms in the anomalies of perception and actions that are usually discussed as selfdeception. This paper suggests that an understanding of self-deception as a psychological phenomenon requires consideration of individual differences that can be seen from two perspectives: horizontal (personality theories perspective) or vertical (developmental perspective). The developmental perspective also suggests that other traditions of working with self-deception may have an advantage when dealing with individuals at different stages of development. For example, it seems reasonable to assume that psychodynamic traditions would have more appropriate strategies for those whose dominant concern is self-preservation and who demonstrate classical defense mechanisms such as denial or repression. Existential therapy and coaching on the other hand may be more effective for those with a higher level of awareness of their own role in their self-deceptive tendencies.

On the cultural level of this model, postmodernism offers what could be seen as a challenging perspective to other traditions by questioning the existence of selfdeception in principle. In the culturally dominant paradigm with an orientation to absolute truth this challenge is well justified. The assumption that the side of the story that is hidden in self-deception is verifiable and true needs to be questioned and cannot become a condition for the identification of self-deception. From the developmental perspective individuals are in the process of change in the way they see and understand themselves and their world; individuals' understanding and experience of reality is viewed as a construction of their minds, taking the form of a narrative that typifies the way the person makes sense and meaning from their experience. By implication, a narrative is limited in content. It contains what is most 
meaningful for its creator, but necessarily leaves out elements of experience that pass unnoticed. Thus immersion in one narrative may lead to something missed out of another, potentially created by a different module from the micro-level perspective. It is also important to emphasize that in certain circumstances some narratives can be verified thus questioning in turn the absolutism of the postmodernist perspective itself.

It is interesting that both the biological level and the cultural level, considered on their own, can be seen as a justification of self-deception and thus opposite to the intention of this paper. However, they could be useful for those individuals interested in self-development and the practitioners assisting them. As part of the proposed conceptual model, understanding these perspectives creates a rich and multidimensional picture of this phenomenon that can help to develop a systemic view on this phenomenon with the added depth of contextual factors such as culture, evolution and the structure of the brain. The complexity of self-deception as presented in this model highlights that the clear-cut definition of it is an unresolved issue; because of such complexity, definition of this concept remains elusive. It is possible that self-deception could only be identified and addressed with the consideration of many factors and observations about individuals in their developmental processes and various contexts. However, the realization of such complexity may also encourage individuals themselves, therapists and coaches to approach it with compassion and curiosity rather than with disapproval and concern.

\section{Conclusion}

It seems undeniable that the concept of self-deception is meaningful for individuals. People are able to recognize these experiences retrospectively and usually do not want to deceive themselves. The realization of being involved in self-deception is often a strong stimulus for personal development and potentially - for wider social change. This paper explored 
the concept of self-deception and several distinct theoretical perspectives with their potential value for individuals who wish to deceive themselves less and for 'helping' practitioners. A new proposed perspective highlighted a developmental aspect of individual differences indicating useful avenues for practitioners to explore in their work.

For a pragmatist, this inquiry also provided an opportunity to create a unique synthesis of the explanations of self-deception. This new developmentally informed explanation of self-deception helps to account for many aspects of the complexity and multifaceted nature of self-deception with the added value of other perspectives. In addition to extending our understanding of this phenomenon it can rejuvenate the interest of researchers in self-deception and suggest exploration of new meaningful questions.

\section{References}

Adams, G. \& Fitch, S. (1982). Ego stage and identity status development: A cross sequential analysis. Journal of Personality and Social Psychology, 43, 574-583. Bachkirova, T. (2013). Developmental coaching: Developing the Self. In J. Passmore, D. Peterson \& T. Freire (Eds.), The Wiley-Blackwell Handbook of the Psychology of Coaching and Mentoring (pp. 135-154). Chichester: John Wiley and sons Ltd.

Bachkirova, T. (2011). Developmental Coaching: Working with the self. Maidenhead: Open University Press.

Balcetis, E. \& Dunning D. (2010). Wishful seeing: Desired objects are seen as closer, Psychological Science, 21, 147-152.

Bandura, A. (2011). Self-deception: A paradox revisited (Open peer commentary on von Hippel \& Trivers, 2011). Behavioral and Brain Sciences, 34 (1), 16-17. 
Bayne, T. \& Fernandez, J. (Eds.) (2009). Delusion and Self-deception: Affective and Motivational Influences on Belief Formation, New York: Taylor and Frances Group. Barrett, H. C. (2005). Enzymatic computation and cognitive modularity. Mind and Language, 20, 259-87.

Berglas, S. (2002). The very real dangers of executive coaching, Harvard Business Review, 80(6), 86-92.

Bonanno, G. \& Siddique, H. (1999). Emotional dissociation, self-deception, and psychotherapy. In J. Singer \& P. Salovey (Eds.), At play in the field of consciousness: Essays in honor of Jerome L. Singer (pp. 249-270). Hillsdale, NJ: Erbaum.

Bruner, J. \& Goodman, C. (1947). Value and need as organizing factors in perception, Journal of Abnormal and Social Psychology, 42, 33-44.

Campbell, J. (1986). Similarity and uniqueness: The effects of attribute type, relevance, and individual differences in self-esteem and depression. Journal of Personality and Social Psychology, 50, 282-294.

Claxton, G. (1994). Noises from the Darkroom. London: Aquarian.

Claxton, G. (1997). Hare Brain Tortoise Mind: Why Intelligence Increases When You Think Less. London: Fourth Estate.

Claxton, G. (2005). Mindfulness, Learning and the Brain. Journal of Rational-Emotive \& Cognitive-Behavior Therapy, 23(4), 301-314.

Claxton, G. (2006). The wayward mind: An intimate history of the unconscious. London: Abacus.

Clegg, J, \& Moissinac, L. (2005). A relational theory of self-deception, New Ideas in Psychology, 23, 96-110.

Conway, M. \& Ross, M. (1984). Getting what you want by revising what you had. Journal of Personality and Social Psychology, 47, 738-48. 
Cook-Greuter, S. (1999). Postatonomous ego development: its nature and measurement. Unpublished Doctoral dissertation. Cambridge, MA: Harvard Graduate School of Education.

Cooper, M. (2005). Therapists' experiences of relational depth: A qualitative interview study. Counselling \& Psychotherapy Research, 5, 87-95.

Darwall, S. (1988). Self-Deception, Autonomy, and Moral Constitution. In B. McLaughlin \& A. Rorty (Eds), Perspectives on Self-Deception (pp. 407-430). Berkeley: University of California Press.

Davidson, D. (1985). Deception and division. In E. LePore \& B. McLaughlin (Eds.), Actions and events (pp. 138-148). Oxford: Blackwell

Demos, R. (1960). Lying to Oneself. Journal of Philosophy, 57, 588-595.

Ellis, A. (1994). Reason and emotion in psychotherapy (rev. and updated). New York:

Birch Lane Press.

Ferguson, M. (2008). On becoming ready to pursue a goal you don't know you have:

Effects of nonconscious goals on evaluative readiness. Journal of Personality and Social Psychology, 95, 1268-1294.

Fingarette, H. (2000). Self-Deception. London: University of California Press.

Fingarette, H. (1998). Self-Deception Needs No Explaining. The Philosophical Quarterly, 48, Issue 192, 289-301.

Freire, T. (2013). Positive Psychology Approaches. In J. Passmore, D. Peterson \& T. Freire (Eds.), The Wiley-Blackwell Handbook of the Psychology of Coaching and Mentoring (pp. 426-443). Chichester: John Wiley and sons Ltd.

Freud, S. (1950). Splitting of the Ego in the Defensive Process. In J. Strachey (Ed.), Collected Papers (Vol V, pp. 372-375). London: Hogarth Press (Original work published 1938). 
Freud, S. (1962). The ego and the id. New York: Norton (Original work published 1923).

Freud, S. (2002). Civilization and Its Discontents, London: Penguin (Original work published 1930).

Fodor, J. (1983). Modularity of Mind: An Essay on Faculty Psychology. Cambridge, Mass.: MIT Press.

Funder, D. (2011). Directions and beliefs of self-presentational bias (Open peer commentary on von Hippel and Trivers, 2011). Behavioral and Brain Sciences, 34(1), $22-$ 23.

Huang, J. \& Bargh, J. (2011). The selfish goal: Self-deception occurs naturally from autonomous goal operation (Open peer commentary on von Hippel \& Trivers, 2011). Behavioral and Brain Sciences, 34 (1), 27-28.

Gazzaniga, M. (1992). Nature's Mind. London: Basic Books.

Gergen, K.J. (1985). The ethnopsychology of self-deception. In M.W. Martin, (Ed.), Selfdeception and self-understanding (pp. 228-243). Lawrence, KS: University Press of Kansas.

Graves, C. (1970). Levels of Existence: An Open system Theory of Values. Journal of Humanistic Psychology, 10(2), 131-155.

Gur, R. \& Sackheim, H. (1979). Self-Deception: A Concept in Search of a Phenomenon, Journal of Personality and Social Psychology, 37, 147-169.

Kauffman, C., Boniwell, I. \& Silberman, J. (2010). The Positive Psychology Approach to Coaching. In E. Cox, T. Bachkirova \& D. Clutterbuck (Eds.), The Complete Handbook of Coaching (pp. 158-171). London: Sage.

Kegan, R. (1994). In Over Our Heads. London: Harvard University Press.

Kegan, R. (1982). The Evolving Self: Problem and Process in Human Development. London: Harvard University Press. 
King, P. M., \& Kitchener, K. S. (1994). Developing reflective judgment: Understanding and promoting intellectual growth and critical thinking in adolescents and adults. San Francisco: Jossey-Bass.

Kenrick, and White (2011). A single self-deceived or several subselves divided? (Open peer commentary on von Hippel and Trivers, 2011). Behavioral and Brain Sciences, 34(1), 29-30.

Kirby, S. (2003). Telling lies? An exploration of self-deception and bad faith. European Journal of Psychotherapy, Counselling and Heath, 6, 99-110.

Kohlberg, L. (1969). Stages in the development of moral thought and action. New York: Holt, Reinhart and Winston.

Kunda, Z. (1990). The case for motivated reasoning. Psychological Bulletin, 108, 480-98. Kurzban, R. (2011). Why everyone (else) is a hypocrite: Evolution and the modular mind. Princeton, NJ: Princeton University Press.

Lee, S. \& Klein, J. (2002). Relationships Between Conscientiousness, Self-Efficacy, SelfDeception, and Learning Over Time. Journal of Applied Psychology, 87(6), 1175-1182. Lewis, B. (1996). Self-Deception: A Post Modern Reflection. Journal of Theoretical and Philosophical Psychology, 16(1), 49-66.

Loevinger, J. (1976). Ego Development: conceptions and theories. San Francisco: JosseyBass.

Manners, J. \& Durkin, K. (2001). A Critical Review of the Validity of Ego Development Theory and Its Measurement. Journal of Personality Assessment, 77(3), 541-567. Martindale, C. (1980). Subselves. In I. Wheeler (Ed.), Review of Personality and Social Psychology (pp. 193-218). Beverly Hills, CA: Sage. 
Marraffa, M. (2012). Remnants of Psychoanalysis. Rethinking the Psychodynamic Approach to Self-deception. Humana Mente: Journal of Philosophical Studies, 20, $223-$ 243.

Maze, J. and \& Henry, R. (1996). Problems in the concept of repression and proposals for their resolution. International Journal of Psycho-analysis, 77,1085-1100.

Mele, A. (2001). Self-Deception Unmasked, Princeton and Oxford: Princeton University Press.

Paulhus, D. (1991). Measurement and control of response bias. In J. Robinson, P. Shaver \& L. Wrightsman, (Eds.) Measures of personality and social psychological attitudes (pp. 1759). San Diego, CA: Academic Press.

Perls, F., Hefferline, R. \& Goodman, P. (1951). Gestalt Therapy. New York: Julian Press. Perry, W.G. (1970). Forms of Intellectual and Ethical Development in the College Years. New York: Holt, Rinehart and Winston, Inc.

Piaget, J. (1976). The Psychology of Intelligence. New Jersey: Littlefield, Adams \& Co. Pinker, S. (1997). How the mind works. New York, NY: W.W. Norton \& Company. Pinker, S. (2008). One on one with Steve Pinker. The Psychologist, 21(2), 184.

Preti, A. \& Miotto, P. (2006). Mental disorders, evolution and inclusive fitness. Behavioral and Brain Sciences, 29, 419-420.

Redmore, C. (1983). Ego development in the college years: Two longitudinal studies. Journal of Youth and Adolescence, 12, 301-306.

Rorty, A. (1994). User-Friendly Self-Deception, Philosophy, 69 (268), 211-228.

Sackeim, H. A. (1983). Self-deception, self-esteem, and depression: The adaptive value of lying to oneself. In J. Masling (Ed.), Empirical studies of psychoanalytical theories (pp. 101-157). Hillsdale, NJ: Erlbaum. 
Sartre, J-P. (1956). Being and Nothingness. (H. E. Barnes, Trans). New York:

Philosophical Library.

Spinelli, E. (2007). Practicing existential psychotherapy: The relational world. London:

Sage.

Starek, J. \& Keating C. (1991). Self-deception and Its Relationship to Success in

Competition. Basic and Applied Social Psychology, 12(2), 145-155.

Stich, S. (1990). The Fragmentation of Reason. MIT Press.

Suls, J. \& Wan, C. (1987). In search of the false-uniqueness phenomenon: Fear and estimates of social consensus. Journal of Personality and Social Psychology, 52, 211-217.

Tenbrunsell, A. \& Messick, D. (2004). Ethical Fading: A Role of Self-Deception in Unethical Behavior. Social Justice Research, 17(2), 223-236.

Tooby, J. \& Cosmides, L. (1992). The psychological foundations of culture. In J. H.

Barkow, L. Cosmides \& J. Tooby (Eds.), The adapted mind: Evolutionary psychology and the generation of culture (pp. 19-136). Oxford: Oxford University Press.

Torbert, W. and Associates. (2004). Action Inquiry: The Secret of Timely and Transforming Leadership. San Francisco, CA: Berret-Koehler Publishers, Inc.

Trivers, R. (2000). The Elements of Scientific Theory of Self-deception. Annals of the New York Academy of Sciences, 907, 114-31.

Vaillant, G. (1992). Ego Mechanisms or Defense: A Guide for Clinicians and Researchers. Washington, DC: American Psychiatric Press, Inc.

Veltkamp, M., Aarts, H. \& Custers, R. (2008). Perception in the service of goal pursuit: Motivation to attain goals enhances the perceived size of goal-instrumental objects. Social Cognition, 26, 720-736.

Von Hippel, W. \& Trivers, R. (2011). The evolution and psychology of self-deception. Behavioral and Brain Sciences, 34, 1-56. 
Westenberg, P. \& Gjede, P. (1999). Ego development during the transition form adolescence to young adulthood: A 9-year longitudinal study. Journal of Research in Personality, 33, 233-252.

Westland, S. \& Shinebourne, P. (2009). Self-deception and the therapist: An interpretative phenomenological analysis of the experiences and understandings of therapists working with clients they describe as self-deceptive. Psychology and Psychotherapy: Theory, Research and Practice, 82 (4), 385-401.

Whisner, W. (1993). Overcoming rationalization and self-deception: The cultivation of critical thinking. Educational Theory, 43 (3), 309-321.

Williams, H., Edgerton, N. \& Palmer, S. (2010). Cognitive behavioral coaching. In E. Cox, T. Bachkirova \& D. Clutterbuck (Eds.), The Complete Handbook of Coaching (pp. 37-53). London: Sage.

Zuckerman, M., Koestner, R. \& Alton, A. O. (1984). Learning to detect deception. Journal of Personality and Social Psychology, 46, 519-28. 